\title{
Role of Dendritic Cells in Natural Immune Control of HIV-1 Infection
}

\author{
Enrique Martin-Gayo ${ }^{1 *}$ and Xu G. Yu ${ }^{2 *}$ \\ ${ }^{1}$ Hospital Universitario de la Princesa, Universidad Autónoma de Madrid, Madrid, Spain, ${ }^{2}$ Ragon Institute of MGH, MIT, and \\ Harvard, Massachusetts General Hospital, Harvard Medical School, Boston, MA, United States
}

OPEN ACCESS

Edited by:

Paul Urquhart Cameron, The University of Melbourne, Australia

Reviewed by:

Philippe Benaroch,

Centre National de la Recherche

Scientifique (CNRS), France Laura Fantuzzi,

Istituto Superiore di Sanità (ISS), Italy

${ }^{*}$ Correspondence:

Enrique Martin-Gayo

enrique.martin@uam.es

$X u G . Y u$

xyu@mgh.harvard.edu

Specialty section:

This article was submitted to

Viral Immunology,

a section of the journal

Frontiers in Immunology

Received: 21 March 2019

Accepted: 22 May 2019

Published: 06 June 2019

Citation:

Martin-Gayo E and Yu XG (2019) Role of Dendritic Cells in Natural Immune

Control of HIV-1 Infection.

Front. Immunol. 10:1306. doi: 10.3389/fimmu.2019.01306
Dendritic cells (DCs) are professional antigen-presenting cells that link innate and adaptive immunity and are critical for the induction of protective immune responses against pathogens. Proportions of these cells are markedly decreased in the blood of untreated HIV-1-infected individuals, suggesting they might be intrinsically involved in HIV-1 pathogenesis. However, despite several decades of active research, the precise role and contribution of these cells to protective or detrimental host responses against HIV-1 are still remarkably unclear. Recent studies have shown that DCs possess a fine-tuned machinery to recognize HIV-1 replication products through a variety of innate pathogen sensing mechanisms, which may be instrumental for generating both cellular and humoral protective immune responses in persons who naturally control HIV-1 replication. Yet, dysregulated and abnormal activation of DCs might also contribute to sustained inflammation and immune activation accelerating disease progression during chronic progressive infection. Emerging data also suggest that DCs can influence the induction of potent broadly-neutralizing antibodies, and may, for this reason, have to be considered as important components of future HIV-1 vaccination strategies. Apart from their involvement in antiviral host immunity, at least a subgroup of DCs seem intrinsically susceptible to HIV-1 infection and may serve as a viral target cell population. Indeed recent studies suggest that specific DC subpopulations residing in the genital mucosa are preferentially infected by HIV-1 and play an active role in sexual transmission; therefore, DCs may contribute to viral dissemination and possible persistence of the viral reservoirs through either direct or indirect mechanisms. Here, we analyze the distinct and partially opposing roles of DCs during HIV-1 disease pathogenesis, with a focus on implications of DC biology natural immune control and HIV cure research efforts.

Keywords: dendritic cell, HIV-1 controller, IFN, Tfh, bNAb, vaccine

\section{INTRODUCTION}

Dendritic cells (DCs) represent a heterogeneous family of immune cells that link innate and adaptive immunity. The main function of these innate cells is to capture, process, and present antigens to adaptive immune cells and mediate their polarization into effector cells (1). DCs can be subdivided in two main subtypes: plasmacytoid (pDC) and myeloid (mDC) DCs, which specialize in the recognition of different pathogen associated molecular patterns (PAMPs) due to the unique distribution of Pattern Recognition Receptors (PRR), such as toll-like receptors, C-type lectins and intracellular nucleic acid sensors (2-4). As a result, mDCs and pDCs can efficiently induce $\mathrm{CD}^{+}{ }^{+}$and $\mathrm{CD}^{+} \mathrm{T}$ cell responses against different types of pathogens. In addition, both mDCs 
and pDCs are also capable of interacting with Natural Killer (NK) cells, which are particularly relevant during viral infections (5). Therefore, the contribution of different DC subtypes to immune responses against microbial infections seems to be highly complex and be influenced by context- and pathogendependent factors.

During HIV-1 infection, several effector components of the innate and adaptive immune system are involved in the host antiviral response, and although these immune responses seem unable to prevent the establishment of the infection, they can influence HIV-1 disease progression. Effective immune control of HIV-1 infection occurs in rare population of HIV1 infected individuals who are able to spontaneously control HIV-1 replication in the absence of antiretroviral therapy, and to maintain undetectable levels of viral replication as measured by commercial PCR assays. In these individuals, long-lived polyfunctional HIV-1-specific $\mathrm{CD}^{+} \mathrm{T}$ cells have been identified as the main biological correlate of spontaneous immune control of HIV-1 (6-8). However, the contribution of DCs to durable immune control of HIV-1 is still a relatively unexplored area and a matter of active debate. During the last years, new relevant data about DC biology in the context of HIV-1 infection have become available, specifically with regards to DC susceptibility to infection, to DC-mediated immune regulation and to direct hostpathogen interactions between DC and HIV-1. In this review, we have focused on consolidating the most recent advances on DC biology in the context of HIV-1 immunopathology, and on providing a detailed evaluation of the role of DC in HIV-1 immune control.

\section{ANATOMICAL LOCALIZATION AND ACTIVATION OF DCs DURING HIV/SIV INFECTION}

DCs are physiologically distributed in mucosal and lymphoid tissues where they capture antigens and present them to T cells, but a small proportion of $\mathrm{mDCs}$ and $\mathrm{pDCs}$ are also circulating in the blood. mDCs can be identified as lineage marker negative cells that display high surface levels of CD11c and HLA-DR

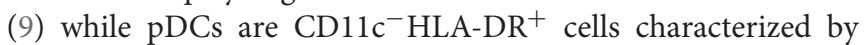
surface expression of the C-type lectin BDCA2, high levels of the alpha chain of the receptor for interleukin-3 (CD123) and the immunoglobulin superfamily receptor immunoglobulin-like transcript 7 (ILT7) (10). Upon HIV-1 infection, the anatomical distribution of DCs is dramatically altered and lower proportions of pDCs and $\mathrm{mDCs}$ are present in the blood of infected untreated individuals (11-13). The extent of the depletion of circulating $\mathrm{mDC}$ is correlated with rapid disease progression during HIV-1 and SIV infections $(14,15)$. Interestingly, proportions of circulating pDCs are more profoundly reduced in HIV1 progressors in contrast to controllers (16); although the exact mechanisms responsible for these differences remain unknown. Despite these discrepancies, circulating pDCs from both controllers and progressors are characterized by upregulated expression of the gut homing integrin $\alpha 4 \beta 7$, suggesting selective trafficking to mucosal intestinal tissue where the majority of
HIV-1-infected cells reside (17). Similarly, higher levels of activation in gut resident $\mathrm{mDCs}$ and $\mathrm{pDCs}$ seem to be associated with changes in gut microbiota and immune homeostasis (18). In addition to migration to the gut, preferential recruitment of pDCs to the lymph nodes also occurs in HIV-1-infected subjects (19).

Besides the changes in anatomical distribution, circulating and tissue-resident DCs display an activated phenotype defined by upregulation of costimulatory molecules in infected individuals (11-13). In fact, higher levels of activation in blood DCs seem to correlate with plasma viremia in progressors (20). In contrast, less pronounced phenotypical signs of immune activation, combined with increased functionality have been described in mDCs from the blood of HIV controllers (21). Interestingly, highly activated mDCs residing in the lymph nodes from $\mathrm{HIV}-1^{+}$patients seem to co-express inhibitory costimulatory molecules such as PD-L1 and are still capable of responding to TLR stimulation, in contrast to cells from peripheral blood (19).

A hallmark of circulating pDCs from the blood of HIV$1^{+}$individuals is the expression of high basal levels of type I interferon (IFN) and IFN-stimulated genes, likely reflecting abnormal immune activation (22). Interestingly, this higher baseline activation of IFN-dependent immune activity seems to make $\mathrm{pDCs}$ from progressors refractory to antigenic stimulation $(23,24)$, and paradoxically reduces their ability to secrete appropriate levels of IFN- $\alpha$ upon PRR stimulation. In contrast, $\mathrm{pDCs}$ from controllers maintain IFN- $\alpha$ secretion levels that are comparable to those of healthy individuals. Consistent with these findings, microscopy-based studies indicated differences in the trafficking of intracellular TNF-related apoptosis-inducing ligand (TRAIL) in pDCs from controllers and healthy donors compared to progressors. TRAIL is a molecule known to induce apoptosis of $\mathrm{CD} 4^{+} \mathrm{T}$ cells through a mechanism regulated by the alarmin High Mobility Group Box 1 (HMGB1) $(23,25)$. While TRAIL seems to be recycled from the membrane of pDCs in controllers after exposure to HIV-1, pDCs from viremic patients appear to constitutively express TRAIL on the membrane, which may contribute to unspecific induction of cell death in $\mathrm{CD} 4^{+} \mathrm{T}$ cells and accelerate cell loss and immunodeficiency (26) (Figure 1). Overall, these data indicate that pDCs from controllers maintain a functional profile that is similar to healthy persons. In contrast, $\mathrm{pDCs}$ from progressors exhibit a hyperactivated state characterized by constitutive TRAIL up-regulation, higher basal levels of IFN-dependent immune responses, and a reduced ability to produce IFN- $\alpha$ in responses to antigen exposure, most likely as a result of generalized immune activation that makes cells refractory to microbial stimulation (Figure 1). The normal functional profile of pDCs in controllers therefore could be a consequence, rather than a cause of viral immune control. Notably, the initiation of antiretroviral therapy does not revert the decline in $\mathrm{pDC}$ frequency and function observed during progressive infection, suggesting an irreversible defect in pDC physiology in progressors after prolonged exposure to high viremia (27). Interestingly, less pathogenic HIV-2 strains induce lower levels of type I IFN expression in pDCs compared to HIV-1, suggesting that lower levels of pDC activation could be associated with immune control of the infection (28). In addition to pDCs, 


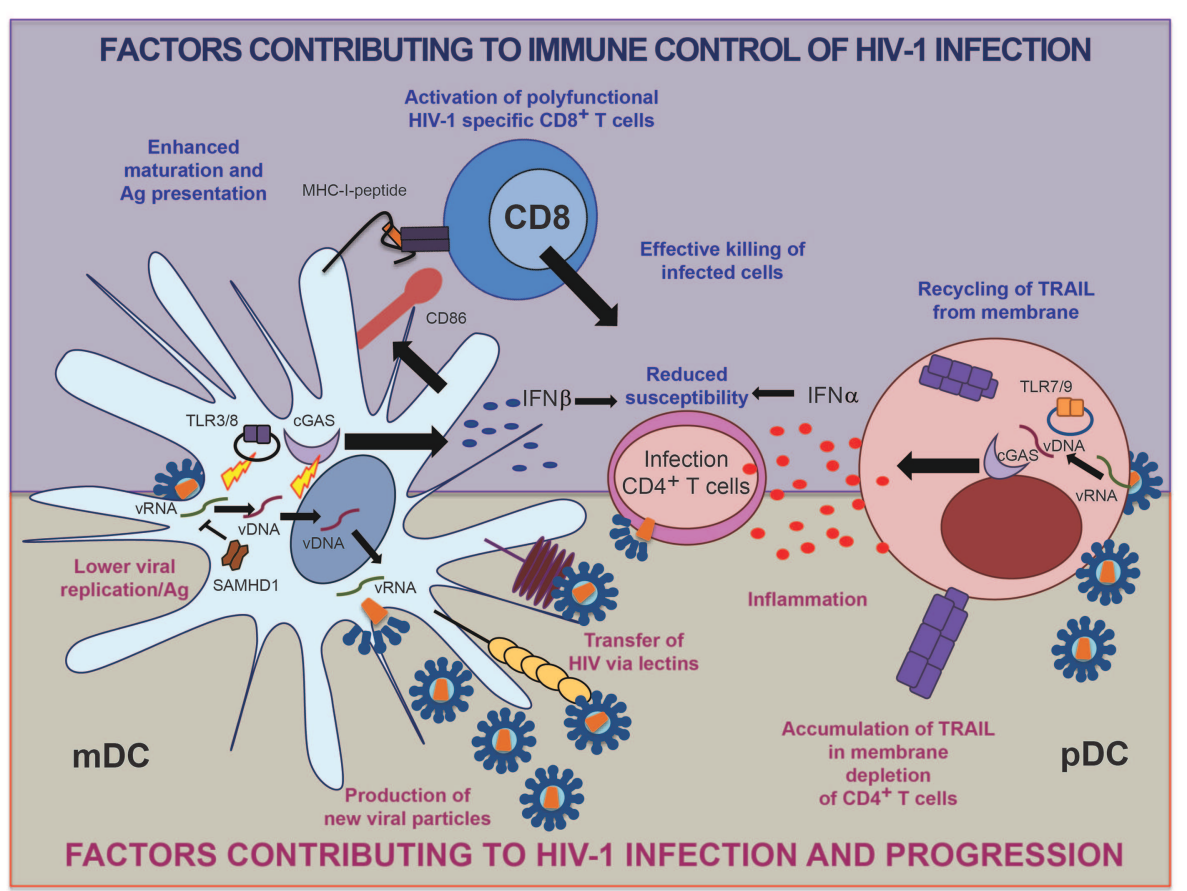

FIGURE 1 | Schematic representation of factors in human $\mathrm{mDC}$ and $\mathrm{pDC}$ contributing to immune control vs. progression of HIV-1 infection.

recent works in the SIV model have suggested that additional cell types might be responsible for abnormal activation of type I IFN responses at later stages of progressive infection (29). Together, cumulative information from recent studies suggests that DC distribution and function might be critically altered during HIV1 infection and that preservation of physiological DC distribution and function is associated with immune control of the infection.

\section{DCs AS VEHICLES FOR HIV-1 TRANSMISSION AND DISSEMINATION}

During the last few years, several studies have shown that DCs have the ability to transfer HIV-1 particles to target $\mathrm{CD} 4^{+} \mathrm{T}$ cells and facilitate their infection, in a process known as transinfection (30). This phenomenon starts with the transference of HIV-1 virions to pockets in the membrane of DCs, where they accumulate and are subsequently actively transferred to $\mathrm{T}$ cells through virological synapses (31). The stability of such transmission events depends on the expression of adhesion molecules, such as Intercellular Adhesion Molecule (ICAM) (32) and the actin assembly machinery (33). In order to transfer viruses to $\mathrm{CD} 4^{+} \mathrm{T}$ cells, DCs require the capture of HIV-1 particles through the lectin Dendritic Cell Intercellular Adhesion Molecule-3-Grabbing Non-integrin (DC-SIGN) (34, 35 ), and the Sialic acid-binding Immunoglobulin-type Lectin 1 (SIGLEC-1) receptor (36). Recent reports have shown that the ability of DCs to facilitate HIV-1 trans-infection is acquired upon activation with inflammatory molecules associated with poor HIV-1 prognosis, such as IFN $\alpha$ and LPS (37). These stimuli have been shown to induce SIGLEC-1 expression and therefore, enhance the capture and transfer of viral particles. Notably, circulating mDCs but not pDCs facilitate transinfection of HIV-1 (32). Therefore, increased basal levels of immune activation and high-level viremia might contribute to disease progression through facilitation of viral transinfection by mDCs. Consistent with a role of $\mathrm{mDCs}$ in supporting HIV-1 trans-infection in lymphoid tissues, it was shown that depletion of lymph node-resident mDCs in tissuesuspension cultures reduced the efficiency of HIV-1 infection of $\mathrm{CD}^{+} \mathrm{T}$ cells (38). However, mutations of SIGLEC-1, which naturally occur in small proportions of individuals, did not seem to provide protection from HIV-1 infection or attenuation of HIV-1 disease progression (39), suggesting that classical, SIGLEC-1-independent HIV-1 dissemination within in the host remains the predominant mechanisms fueling viral infection in vivo.

\section{SUSCEPTIBILITY TO HIV-1 INFECTION AND HOST RESTRICTION FACTORS}

Most DCs express the coreceptor CD4 (40), and therefore are in principle susceptible to infection with HIV-1. However, DCs seem to represent a more hostile and restrictive environment for HIV-1 than $\mathrm{CD}^{+}{ }^{+} \mathrm{T}$ cells, for reasons that are not completely clear. While initial studies suggested that monocyte derived DCs (MDDCs) are highly resistant to infection with HIV-1 (41), primary mDCs are able to support some levels of HIV-1 replication, at least in vitro (42-44). 
The main restriction factor that limits HIV-1 replication in MDDCs and mDCs seems to be the cytoplasmic protein SAM domain and HD domain-containing protein 1 (SAMHD1), which is highly expressed in myeloid cells and is able to block HIV-1 replication at the retro-transcription level by depleting endogenous intracellular pools of dNTPs (45), and by directly degrading viral RNA (46). While it is clear that SAMHD1 is a key factor limiting replication of HIV-1 in MDDCs (47) and inhibiting further spread of virions to T cells (48), recent studies demonstrated that MDDCs can actually support productive infection with HIV-1 to a certain degree, despite high levels of expression of this restriction factor (49). The functional ability of SAMHD1 to restrict HIV-1 replication is regulated by phosphorylation mediated by host kinases from the cyclindependent kinase family (50). Interestingly, the functionally active, de-phosphorylated form of SAMHD1 is preferentially found in primary DCs isolated ex vivo from human blood, which potentially could contribute to a higher resistance to infection (51). However, it is unclear whether restriction of HIV-1 by SAMHD1 in mDCs might truly benefit the host, since restriction of HIV-1 replication via SAMHD1 may impair cytoplasmic viral immune recognition in $\mathrm{mDC}$ and impair their ability to prime HIV-1-specific $\mathrm{T}$ cells. On the other hand, interactions of $\mathrm{mDCs}$ with $\mathrm{T}$ cells induce downregulation of SAMHD1 expression (52), allowing human primary $\mathrm{mDCs}$ to be more permissive to infection (44). Importantly, recent data indicate that primary $\mathrm{CD} 1 \mathrm{c}^{+}$and $\mathrm{CD} 141^{+} \mathrm{mDC}$ subtypes might differ in their susceptibility to HIV-1 infection. In this regard, expression of the endosomal protein RAB15 prevents fusion of viral particles in $\mathrm{CD}_{141^{+}} \mathrm{mDCs}$ and induces a higher level of cell-intrinsic resistance to infection with HIV-1 and HIV-2 compared to $\mathrm{CD} \mathrm{c}^{+}$mDCs (53). Further proof for the susceptibility of primary mDCs to HIV-1 infection was provided by a recent study identifying a distinct population of $\mathrm{CD} \mathrm{a}^{+} \mathrm{mDC}$ residing in the vaginal mucosa, which supported CCR5-tropic but not CXCR4tropic HIV-1 replication, in contrast to vaginal Langerhans cells (LC). These data suggest that these vaginal mDCs might play an active role in the selection of transmitted viral variants during heterosexual HIV-1 acquisition (54).

In the context of immune control of HIV-1 infection, recent studies suggest that monocytes and mDCs from HIV1 controllers restrict early HIV-1 replication steps, specifically at the level of viral integration $(44,55,56)$ while restriction of viral reverse transcription is less obvious, possibly due to lower induction of SAMHD1 expression in HIV-1 controllers upon exposure to HIV-1. This specific replicative pattern of HIV-1 may enable enhanced cytoplasmic sensing of accumulated HIV1 reverse transcripts, which represent the primary substrate for innate immune recognition, and facilitate antigen processing and presentation $(44,56)$. Interestingly, although SAMHD1 is thought to be an interferon inducible gene, DCs and $\mathrm{CD}^{+} \mathrm{T}$ cells fail to induce its expression in the presence of type I IFNs (57). Therefore, higher permissiveness of $\mathrm{mDC}$ from controllers to viral reverse transcription may represent a key element for supporting cytoplasmic detection of HIV-1 and for inducing potent cell-intrinsic responses that lead to the effective activation of HIV-1-specific T cells (Figure 1).
Although SAMHD1 is recognized as a critical host factor limiting HIV-1 replication in myeloid cells, alternative SAMHD1-independent restriction mechanisms might also be playing a role in effective immunological control of HIV-1 replication. Among them, recognition of the HIV-1 capside by cyclophilin A $(41,58)$ and TRIM5 $\alpha(59,60)$ or endogenous levels of $\beta$-catenin (52), could be actively contributing to block HIV-1 replication in myeloid cells. In addition, some studies suggest that HIV-1 could trigger TLR activation in DCs (61). Indeed, activation of MDDCs through TLR4 and TLR3 resulted in inhibition of $\mathrm{HIV}-1$ replication steps in DC, while simultaneously increasing their ability to prime HIV-specific $\mathrm{CD}^{+} \mathrm{T}$ cells (62). Therefore, TLR-dependent activation of DC could play a relevant role for inducing highly-functional cellular immune responses against HIV-1. Supporting this idea, polymorphisms in the TLR3 gene confer resistance to HIV-1 infection (63). In fact, it was recently suggested that TLR activation could be playing an active role in the detection of HIV-1 by primary $\mathrm{CD} 141^{+} \mathrm{mDCs}$ (53). Therefore, more studies are required to investigate the mutual interplay between viral restriction in DCs and immune control of HIV-1, and to determine the contribution of myeloid cells to persisting viral reservoirs during suppressive antiretroviral therapy.

\section{INNATE IMMUNE RESPONSES TO HIV-1 IN DCs}

DCs are, in principle, capable of inducing secretion of type I IFNs upon recognition of viral nucleic acids, which subsequently leads to transcription of interferon stimulated genes (ISGs) and the upregulation of class II HLA and costimulatory molecules. As a result of such cell-intrinsic, IFN-dependent immune responses, mature DCs become more restrictive for viral replication, while the expression of molecules involved in antigen presentation and co-stimulation is increased. Whether $\mathrm{mDCs}$ can induce secretion of type I IFNs in response to HIV-1 is still highly controversial. In MDDCs, HIV-1 seems to be able to induce expression of several IFN-related genes in the absence of actual production of IFN $\alpha / \beta$ due to the selective activation of IRF-1 mediated signaling instead of inducing phosphorylation of IRF3, which is known to be required for induction of type I IFNs (64). However, the intracellular DNA sensor cGAS is expressed by myeloid cells (65) and is able of producing cGAMP second messengers upon recognition of HIV-1 DNA (66), leading to the activation of the sensor STING and the signal transducer TBK-1, which promote IFN $\beta$ production $(67,68)$. Thus, primary DCs are, in principle, able to sense and induce type I IFN upon exposure to cytoplasmic HIV-1 DNA. In fact, activation of cGAS seems to be required for the transcription of IFN $\beta$ by primary mDCs and MDDCs in the context of HIV-1 and other viral infections $(44,69,70)$. This DNA-dependent mechanism of viral sensing leading to type I IFN responses might be more active in human $\mathrm{CD}_{1} \mathrm{c}^{+} \mathrm{mDCs}$ compared to $\mathrm{CD}_{141^{+}}$mDCs (53). Interestingly, cGAS triggers TLR9-independent activation of primary pDCs in response to intracellular DNA $(71,72)$. However, current phenotypic 
markers for pDC identify a heterogenous cell population that, in addition to bona fide $\mathrm{pDC}$, contains pre-DC precursors of mDCs, which could also be differentially contributing to the observed responses to HIV-1 (73). Such heterogeneity could be the result of different pre-pDC and/or pDCs originated from either lymphoid or myeloid precursors with different functional properties (74-76). Therefore, more studies are required to elucidate the contribution of TLR-independent sensing of HIV-1 in pDCs. Finally, activation of the cGAS pathway by HIV-1 might involve interactions with additional host factors such as the newly identified NONO protein, which apparently is able to bind cGAS and the HIV-1 capsid and facilitate innate sensing of HIV-1 DNA in dendritic cells (77).

Importantly, preserved or enhanced induction of IFN responses has been described in both primary pDCs $(23,24)$ and mDCs (44) from HIV-1 controllers exposed to HIV-1. A recent single-cell RNAseq study has identified a highly functional population of $\mathrm{CD} 64{ }^{\mathrm{Hi}} \mathrm{CD} 86^{\mathrm{Hi}} \mathrm{PD}-\mathrm{L} 1{ }^{\mathrm{Hi}} \mathrm{mDC}$ characterized by a strong type I IFN signature that is induced more efficiently in HIV-1 controllers than in progressors or healthy individuals in response to HIV-1 (78). The induction of such highly functional mDCs depended on the activation of TBK-1, which acts downstream of several intracellular sensing pathways including cGAS and TLR-3. Therefore, enhanced innate recognition of HIV-1 by both pDCs and mDCs might be a contributing factor to develop effective HIV-1 specific immunity in these individuals (Figure 1). However, HIV-1 might have evolved to minimize such mechanisms of viral DNA recognition, since HIV-1 Vif and Vpr are capable of inactivating TBK-1 which is downstream of the cGAS-STING pathway (79). Therefore, additional mechanisms such as alterations in the activation threshold of intracellular sensing pathways might be playing a role in DCs from controllers. In addition to sensing of viral DNA by cGAS, viral immune recognition in DCs could be connected with the RIG-I pathway, which may also contribute to activation of DCs in response to HIV-1 (80). In fact, communication and collaboration between RIG-I and DNA sensing pathways has been reported to amplify innate immune responses against intracellular viral DNA $(81,82)$. Although no genetic alterations in genes encoding for innate immune sensors for HIV-1 have been found in GWAS studies including large HIV-1-infected populations, a more targeted analysis of innate immune genes may in the future allow to identify immunogenetic polymorphisms in the innate immune system that facilitate innate immune sensing and natural viral control in specific subgroups of HIV-1 controllers.

\section{ANTIGEN PRESENTING CELL FUNCTION OF DCs AND ADAPTIVE IMMUNITY AGAINST HIV-1}

Given associations between the polyfunctionality of $\mathrm{T}$ cell responses and natural progression of HIV-1 infection (8), several studies have focused on the function of DCs as professional antigen presenting cells (APC) and how these cells are involved in the priming of adaptive immune cells. As mentioned before, both $\mathrm{mDCs}$ and $\mathrm{pDCs}$ can respond and mature to a certain degree in response to HIV-1, but may become exhausted and hyporesponsive during chronic progressive infection, which might impact their antigen-presenting cell function (83). In the case of pDCs, infection with HIV-1 seems to turn these cells more tolerogenic, and increase their potential to drive polarization of $\mathrm{CD}^{+} \mathrm{T}$ cells into immunosuppressive $\mathrm{T}$ regulatory cells (84). On the other hand, although pDCs can activate $\mathrm{CD}^{+}$ $\mathrm{T}$ cells through cross-presentation (85), no studies have yet analyzed the impact of pDCs on the priming of HIV-1-specific cytotoxic $\mathrm{CD}^{+} \mathrm{T}$ cell responses. In contrast, while circulating mDCs from healthy individuals are functionally incapable of efficiently priming T cells in vitro after exposure to HIV-1 (86), effective antigen presenting functions of mDCs from HIV-1 elite controllers is associated with enhanced abilities to prime HIVspecific $\mathrm{CD}^{+} \mathrm{T}$ cells in these patients $(44,78)$. In addition to $\mathrm{mDCs}$, recent in vitro studies have shown that MDDCs can acquire HIV-1 antigens from Langerhans cells, become activated and induce cross-presentation to $\mathrm{CD} 8^{+} \mathrm{T}$ cells (87), suggesting that these cells may also be potentially able to prime protective HIV-1-specific cytotoxic $\mathrm{CD} 8^{+} \mathrm{T}$ cells. In addition, independent studies have shown that MDDCs can mediate cross-presentation of immuno-dominant HIV-1 peptides and activate HIV-1-specific CD8 ${ }^{+} \mathrm{T}$ cells (88). However, MDDC are not a physiological DC subset present and in fact more closely resemble inflammatory DCs (89). Nevertheless, a recent evaluation suggested that primary $\mathrm{CD} 141^{+} \mathrm{mDCs}$, obtain HIV1 antigens from infected $\mathrm{CD}^{+} \mathrm{c}^{+} \mathrm{mDC}$ for cross-presentation to $\mathrm{CD}^{+} \mathrm{T}$ cells (53). Interestingly, DCs infected with HIV-1 can also present endogenous viral peptides and mediate activation of HIV-1-specific CD $4{ }^{+}$T cells (90). Therefore, mDCs and MDDCs might be involved in the priming of effective HIV-1-specific T cell responses observed in controllers.

Although highly functional HIV-1-specific $\mathrm{CD}^{+} \mathrm{T}$ cell responses were identified as the main correlate of antiviral immune defense (91), the discovery of broadly neutralizing antibodies (bNAbs) against multiple strains of HIV-1 (92, 93), has led to a great interest in understanding their potential contribution to spontaneous immunological control of HIV-1. Recent works have indeed identified a subpopulation of HIV-1 viremic controllers who develop bNAbs in the absence of high levels of viremia or immune activation (94). In previous studies in viremic HIV-1-infected progressors, the induction of bNAbs was associated with the presence of CXCR $5^{+} \mathrm{PD}-1^{+} \mathrm{T}$ follicular helper cells (Tfh) in the blood (95). Although Tfh cells facilitate B cell maturation and immunoglobulin class switching in lymphoid tissue (96), peripheral CXCR5 ${ }^{+} \mathrm{PD}-1^{+} \mathrm{CD} 4^{+} \mathrm{T}$ lymphocytes have been proposed to act as peripheral counterparts of Tfh cells (pTfh) $(95,97)$ and could serve as a peripheral biomarker of high germinal center Tfh cell activity. Therefore, the priming of Tfh cells by mDC might be important in HIV-1 controllers capable of inducing antibodies with broader neutralizing activity. Supporting this possibility, mDCs from controller neutralizers are more efficient in priming $\mathrm{CD} 4^{+} \mathrm{T}$ cells into long lived $\mathrm{PD}-1^{\mathrm{Lo}}$ Tfh precursors, which can differentiate into functional PD- ${ }^{\mathrm{Hi}}$ Tfh effector cells upon antigenic stimulation (98). Importantly, higher frequencies of PD- $1^{\text {Lo }}$ Tfh precursors in the blood are 
correlated with higher breadth of $\mathrm{Ab}$ neutralization in this subset of controllers. Compatible with an indirect role of DCs for influencing humoral immunity through polarization of Tfh, mDCs from controller neutralizers are characterized by high levels of CD40, a molecule previously involved in Tfh cell differentiation (99), and display distinct transcriptional patterns that differ from those present in $\mathrm{CD} 64^{\mathrm{Hi}} \mathrm{PD}-\mathrm{L} 1^{\mathrm{Hi}} \mathrm{mDC}$ from elite controllers with high $\mathrm{CD}^{+}{ }^{+} \mathrm{T}$ cell priming potential (98). Therefore, these findings might suggest a range of functional specializations of $\mathrm{mDCs}$ from controllers that may contribute to immune viral control through different immune mechanisms. To which degree individual DC subpopulations influence other components of the innate and adaptive immune system and contribute to control of HIV-1 is still an open question that requires further study.

\section{CONCLUSIONS}

In this review, we have summarized recent advances in understanding DC biology in the context of HIV-1 immune control. While studies have revealed multiple mechanisms by which DCs might contribute to controlling HIV-1 (Figure 1), future studies will be necessary to evaluate the complexity of individual DC subsets in promoting beneficial versus detrimental

\section{REFERENCES}

1. Shortman K, Liu YJ. Mouse and human dendritic cell subtypes. Nat Rev Immunol. (2002) 2:151-61. doi: 10.1038/nri746

2. Jarrossay D, Napolitani G, Colonna M, Sallusto F, Lanzavecchia A. Specialization and complementarity in microbial molecule recognition by human myeloid and plasmacytoid dendritic cells. Eur J Immunol. (2001) 31:3388-93. doi: 10.1002/1521-4141(200111)31:11>3388::AIDIMMU3388<3. $0 . \mathrm{CO} ; 2-\mathrm{Q}$

3. Szabo A, Rajnavolgyi E. Collaboration of Toll-like and RIG-I-like receptors in human dendritic cells: tRIGgering antiviral innate immune responses. Am J Clini Exp Immunol. (2013) 2:195-207.

4. Unterholzner L. The interferon response to intracellular DNA: why so many receptors? Immunobiology. (2013) 218:131221. doi: 10.1016/j.imbio.2013.07.007

5. Marcenaro E, Carlomagno S, Pesce S, Moretta A, Sivori S. NK/DC crosstalk in anti-viral response. Adv Exp Med Biol. (2012) 946:295308. doi: 10.1007/978-1-4614-0106-3_17

6. Blankson JN. Effector mechanisms in HIV-1 infected elite controllers: highly active immune responses? Antiviral Research. (2010) 85:295302. doi: 10.1016/j.antiviral.2009.08.007

7. Hersperger AR, Martin JN, Shin LY, Sheth PM, Kovacs CM, Cosma GL, et al. Increased HIV-specific CD8+ T-cell cytotoxic potential in HIV elite controllers is associated with T-bet expression. Blood. (2011) 117:3799808. doi: 10.1182/blood-2010-12-322727

8. Saez-Cirion A, Lacabaratz C, Lambotte O, Versmisse P, Urrutia A, Boufassa F, et al. HIV controllers exhibit potent CD8 T cell capacity to suppress HIV infection ex vivo and peculiar cytotoxic T lymphocyte activation phenotype. Proc Natl Acad Sci USA. (2007) 104:6776-81. doi: 10.1073/pnas.0611244104

9. Kadowaki N, Ho S, Antonenko S, Malefyt RW, Kastelein RA, Bazan F, et al. Subsets of human dendritic cell precursors express different toll-like receptors and respond to different microbial antigens. J Exp Med. (2001) 194:863-9. doi: 10.1084/jem.194.6.863

10. Tavano B, Galao RP, Graham DR, Neil SJ, Aquino VN, Fuchs D, et al. Iglike transcript 7, but not bone marrow stromal cell antigen 2 (also known as HM1.24, tetherin, or CD317), modulates plasmacytoid dendritic cell effects during HIV-1 infection. Similarly, our knowledge about the intrinsic ability of pDCs and mDCs to sense and respond to HIV-1 has greatly improved over the last few years, but translating this insight into improved and more specific adjuvants for future preventive and therapeutic HIV-1 vaccines represents a considerable challenge. The development to new humanized animal models that recapitulate human DC biology will likely be critical to identify effective vaccination strategies based on DCs. Together, DCs are emerging as critical players of effective immune responses in HIV-1 and a closer understanding of these cells might contribute to the development of novel effective vaccines or immunotherapies.

\section{AUTHOR CONTRIBUTIONS}

EM-G and XY conceived and wrote the manuscript.

\section{FUNDING}

XY is supported by NIH Grants AI078799, HL134539, AI116228, AI125109, DA047034, AI117841, AI114235, AI135940. EM-G was supported by the Programa Atracción de Talento Modalidad 1 from Comunidad de Madrid (2017-T1/BMD-5396) and the NIH R21grant program (AI140930). function in primary human blood leukocytes. J Immunol. (2013) 190:262230. doi: 10.4049/jimmunol.1202391

11. Barron MA, Blyveis N, Palmer BE, MaWhinney S, Wilson CC. Influence of plasma viremia on defects in number and immunophenotype of blood dendritic cell subsets in human immunodeficiency virus 1-infected individuals. J Infect Dis. (2003) 187:26-37. doi: 10.1086/345957

12. Dillon SM, Robertson KB, Pan SC, Mawhinney S, Meditz AL, Folkvord $\mathrm{JM}$, et al. Plasmacytoid and myeloid dendritic cells with a partial activation phenotype accumulate in lymphoid tissue during asymptomatic chronic HIV-1 infection. J Acqu Immune Defic Syndromes. (2008) 48:112. doi: $10.1097 / \mathrm{QAI} .0 \mathrm{~b} 013 \mathrm{e} 3181664 \mathrm{~b} 60$

13. Sabado RL, O’Brien M, Subedi A, Qin L, Hu N, Taylor E, et al. Evidence of dysregulation of dendritic cells in primary HIV infection. Blood. (2010) 116:3839-52. doi: 10.1182/blood-2010-03-273763

14. Diao Y, Geng W, Fan X, Cui H, Sun H, Jiang Y, et al. Low CD1c + myeloid dendritic cell counts correlated with a high risk of rapid disease progression during early HIV-1 infection. BMC Infect Dis. (2015) 15:342. doi: 10.1186/s12879-015-1092-8

15. Malleret B, Karlsson I, Maneglier B, Brochard P, Delache B, Andrieu T, et al. Effect of SIVmac infection on plasmacytoid and CD1c+ myeloid dendritic cells in cynomolgus macaques. Immunology. (2008) 124:22333. doi: 10.1111/j.1365-2567.2007.02758.x

16. Donaghy H, Pozniak A, Gazzard B, Qazi N, Gilmour J, Gotch F, et al. Loss of blood $\mathrm{CD} 11 \mathrm{c}(+)$ myeloid and $\mathrm{CD} 11 \mathrm{c}(-)$ plasmacytoid dendritic cells in patients with HIV-1 infection correlates with HIV-1 RNA virus load. Blood. (2001) 98:2574-6. doi: 10.1182/blood.V98.8.2574

17. Lehmann C, Jung N, Forster K, Koch N, Leifeld L, Fischer J, et al. Longitudinal analysis of distribution and function of plasmacytoid dendritic cells in peripheral blood and gut mucosa of HIV infected patients. J Infect Dis. (2014) 209:940-9. doi: 10.1093/infdis/jit612

18. Cunningham CR, Champhekar A, Tullius MV, Dillon BJ, Zhen A, de la Fuente JR, et al. Type I and type II interferon coordinately regulate suppressive dendritic cell fate and function during viral persistence. PLoS Pathogens. (2016) 12:e1005356. doi: 10.1371/journal.ppat.1005356

19. Carranza P, Del Rio Estrada PM, Diaz Rivera D, Ablanedo-Terrazas Y, Reyes-Teran G. Lymph nodes from HIV-infected individuals harbor mature 
dendritic cells and increased numbers of PD-L1+ conventional dendritic cells. Human Immunol. (2016) 77:584-93. doi: 10.1016/j.humimm.2016.05.019

20. Huang J, Burke P, Yang Y, Seiss K, Beamon J, Cung T, et al. Soluble HLAG inhibits myeloid dendritic cell function in HIV-1 infection by interacting with leukocyte immunoglobulin-like receptor B2. J Virol. (2010) 84:1078491. doi: 10.1128/JVI.01292-10

21. Huang J, Burke PS, Cung TD, Pereyra F, Toth I, Walker BD, et al. Leukocyte immunoglobulin-like receptors maintain unique antigen-presenting properties of circulating myeloid dendritic cells in HIV-1-infected elite controllers. J Virol. (2010) 84:9463-71. doi: 10.1128/JVI.01009-10

22. Lehmann C, Harper JM, Taubert D, Hartmann P, Fatkenheuer G, Jung N, et al. Increased interferon alpha expression in circulating plasmacytoid dendritic cells of HIV-1-infected patients. J Acquired Immune Defic Syndr. (2008) 48:522-30. doi: 10.1097/QAI.0b013e31817f97cf

23. Barblu L, Machmach K, Gras C, Delfraissy JF, Boufassa F, Leal M, et al. Plasmacytoid dendritic cells (pDCs) from HIV controllers produce interferon-alpha and differentiate into functional killer pDCs under HIV activation. J Infect Dis. (2012) 206:790-801. doi: 10.1093/infdis/jis384

24. Machmach K, Leal M, Gras C, Viciana P, Genebat M, Franco E, et al. Plasmacytoid dendritic cells reduce HIV production in elite controllers. $J$ Virol. (2012) 86:4245-52. doi: 10.1128/JVI.07114-11

25. Saidi H, Bras M, Formaglio P, Melki MT, Charbit B, Herbeuval JP, et al. HMGB1 Is Involved in IFN-alpha production and TRAIL expression by HIV1-exposed plasmacytoid dendritic cells: impact of the crosstalk with NK cells. PLoS Pathog. (2016) 12:e1005407. doi: 10.1371/journal.ppat.1005407

26. Herbeuval JP, Grivel JC, Boasso A, Hardy AW, Chougnet C, Dolan MJ, et al. CD4+ T-cell death induced by infectious and noninfectious HIV-1: role of type 1 interferon-dependent, TRAIL/DR5-mediated apoptosis. Blood. (2005) 106:3524-31. doi: 10.1182/blood-2005-03-1243

27. Lichtner M, Rossi R, Rizza MC, Mengoni F, Sauzullo I, Massetti AP, et al. Plasmacytoid dendritic cells count in antiretroviral-treated patients is predictive of HIV load control independent of CD4+ T-cell count. Curr HIV Res. (2008) 6:19-27. doi: 10.2174/157016208783571937

28. Royle CM, Graham DR, Sharma S, Fuchs D, Boasso A. HIV-1 and HIV-2 differentially mature plasmacytoid dendritic cells into IFN-producing cells or APCs. J Immunol. (2014) 193:3538-48. doi: 10.4049/jimmunol.1400860

29. Kader M, Smith AP, Guiducci C, Wonderlich ER, Normolle D, Watkins SC, et al. Blocking TLR7- and TLR9-mediated IFN-alpha production by plasmacytoid dendritic cells does not diminish immune activation in early SIV infection. PLoS Pathog. (2013) 9:e1003530. doi: 10.1371/journal.ppat.1003530

30. Kijewski SD, Gummuluru S. A mechanistic overview of dendritic cellmediated HIV-1 trans infection: the story so far. Future Virol. (2015) 10:25769. doi: $10.2217 /$ fvl.15.2

31. Dale BM, Alvarez RA, Chen BK. Mechanisms of enhanced HIV spread through T-cell virological synapses. Immunol Rev. (2013) 251:113-24. doi: 10.1111/imr.12022

32. Groot F, van Capel TM, Kapsenberg ML, Berkhout B, de Jong EC. Opposing roles of blood myeloid and plasmacytoid dendritic cells in HIV-1 infection of T cells: transmission facilitation versus replication inhibition. Blood. (2006) 108:1957-64. doi: 10.1182/blood-2006-03-010918

33. Menager MM, Littman DR. Actin dynamics regulates dendritic cell-mediated transfer of HIV-1 to T cells. Cell. (2016) 164:695709. doi: 10.1016/j.cell.2015.12.036

34. Geijtenbeek TB, Kwon DS, Torensma R, van Vliet SJ, van Duijnhoven GC, Middel J, et al. DC-SIGN, a dendritic cell-specific HIV-1-binding protein that enhances trans-infection of T cells. Cell. (2000) 100:58797. doi: 10.1016/S0092-8674(00)80694-7

35. Kwon DS, Gregorio G, Bitton N, Hendrickson WA, Littman DR. DC-SIGNmediated internalization of HIV is required for trans-enhancement of $\mathrm{T}$ cell infection. Immunity. (2002) 16:135-44. doi: 10.1016/S1074-7613(02)00259-5

36. Izquierdo-Useros $\mathrm{N}$, Lorizate $\mathrm{M}$, McLaren PJ, Telenti A, Krausslich HG, Martinez-Picado J. HIV-1 capture and transmission by dendritic cells: the role of viral glycolipids and the cellular receptor Siglec-1. PLoS Pathog. (2014) 10:e1004146. doi: 10.1371/journal.ppat.1004146

37. Pino M, Erkizia I, Benet S, Erikson E, Fernandez-Figueras MT, Guerrero D, et al. HIV-1 immune activation induces Siglec-1 expression and enhances viral trans-infection in blood and tissue myeloid cells. Retrovirology. (2015) 12:37. doi: 10.1186/s12977-015-0160-x
38. Reyes-Rodriguez AL, Reuter MA, McDonald D. Dendritic cells enhance HIV infection of memory CD4(+) T cells in human lymphoid tissues. AIDS Res Human Retroviruses. (2016) 32:203-10. doi: 10.1089/aid.2015.0235

39. Martinez-Picado J, McLaren PJ, Erkizia I, Martin MP, Benet S, Rotger M, et al. Identification of Siglec-1 null individuals infected with HIV-1. Nat Comm. (2016) 7:12412. doi: 10.1038/ncomms12412

40. Patterson S, Rae A, Hockey N, Gilmour J, Gotch F. Plasmacytoid dendritic cells are highly susceptible to human immunodeficiency virus type 1 infection and release infectious virus. J Virol. (2001) 75:67103. doi: 10.1128/JVI.75.14.6710-6713.2001

41. Manel N, Hogstad B, Wang Y, Levy DE, Unutmaz D, Littman DR. A cryptic sensor for HIV-1 activates antiviral innate immunity in dendritic cells. Nature. (2010) 467:214-7. doi: 10.1038/nature09337

42. Smed-Sorensen A, Lore K, Vasudevan J, Louder MK, Andersson J, Mascola JR, et al. Differential susceptibility to human immunodeficiency virus type 1 infection of myeloid and plasmacytoid dendritic cells. J Virol. (2005) 79:88619. doi: 10.1128/JVI.79.14.8861-8869.2005

43. Cameron PU, Handley AJ, Baylis DC, Solomon AE, Bernard N, Purcell DF, et al. Preferential infection of dendritic cells during human immunodeficiency virus type 1 infection of blood leukocytes. J Virol. (2007) 81:2297306. doi: 10.1128/JVI.01795-06

44. Martin-Gayo E, Buzon MJ, Ouyang Z, Hickman T, Cronin J, Pimenova D, et al. Potent cell-intrinsic immune responses in dendritic cells facilitate HIV1-specific T cell immunity in HIV-1 elite controllers. PLoS Pathog. (2015) 11:e1004930. doi: 10.1371/journal.ppat.1004930

45. Lahouassa H, Daddacha W, Hofmann H, Ayinde D, Logue EC, Dragin L, et al. SAMHD1 restricts the replication of human immunodeficiency virus type 1 by depleting the intracellular pool of deoxynucleoside triphosphates. Nat Immunol. (2012) 13:223-8. doi: 10.1038/ni.2236

46. Ryoo J, Choi J, Oh C, Kim S, Seo M, Kim SY, et al. The ribonuclease activity of SAMHD1 is required for HIV-1 restriction. Nat Med. (2014) 20:936-41. doi: 10.1038/nm.3626

47. Hrecka K, Hao C, Gierszewska M, Swanson SK, Kesik-Brodacka M, Srivastava S, et al. Vpx relieves inhibition of HIV-1 infection of macrophages mediated by the SAMHD1 protein. Nature. (2011) 474:658-61. doi: 10.1038/nature10195

48. Puigdomenech I, Casartelli N, Porrot F, Schwartz O. SAMHD1 restricts HIV1 cell-to-cell transmission and limits immune detection in monocyte-derived dendritic cells. J Virol. (2013) 87:2846-56. doi: 10.1128/JVI.02514-12

49. Hertoghs N, van der Aar AM, Setiawan LC, Kootstra NA, Gringhuis SI, Geijtenbeek TB. SAMHD1 degradation enhances active suppression of dendritic cell maturation by HIV-1. J Immunol. (2015) 194:44317. doi: $10.4049 /$ jimmunol.1403016

50. Cribier A, Descours B, Valadao AL, Laguette N, Benkirane M. Phosphorylation of SAMHD1 by cyclin A2/CDK1 regulates its restriction activity toward HIV-1. Cell Rep. (2013) 3:103643. doi: 10.1016/j.celrep.2013.03.017

51. Bloch N, O’Brien M, Norton TD, Polsky SB, Bhardwaj N, Landau NR. HIV type 1 infection of plasmacytoid and myeloid dendritic cells is restricted by high levels of SAMHD1 and cannot be counteracted by Vpx. AIDS Res Human Retroviruses. (2014) 30:195-203. doi: 10.1089/aid.2013.0119

52. Aljawai Y, Richards MH, Seaton MS, Narasipura SD, Al-Harthi L. beta-Catenin/TCF-4 signaling regulates susceptibility of macrophages and resistance of monocytes to HIV-1 productive infection. Curr HIV Res. (2014) 12:164-73. doi: 10.2174/1570162X12666140526122249

53. Silvin A, Yu CI, Lahaye X, Imperatore F, Brault JB, Cardinaud S, et al. Constitutive resistance to viral infection in human CD141(+) dendritic cells. Sci Immunol. (2017) 2:eaai8071. doi: 10.1126/sciimmunol.aai8071

54. Pena-Cruz V, Agosto LM, Akiyama H, Olson A, Moreau Y, Larrieux JR, et al. HIV-1 replicates and persists in vaginal epithelial dendritic cells. J Clini Invest. (2018) 128:3439-44. doi: 10.1172/JCI98943

55. Saez-Cirion A, Hamimi C, Bergamaschi A, David A, Versmisse P, Melard A, et al. Restriction of HIV-1 replication in macrophages and CD4+ T cells from HIV controllers. Blood. (2011) 118:955-64. doi: 10.1182/blood-2010-12327106

56. Hamimi C, David A, Versmisse P, Weiss L, Bruel T, Zucman D, et al. Dendritic cells from HIV controllers have low susceptibility to HIV-1 infection in vitro but high capacity to capture HIV-1 particles. PLOS ONE. (2016) 11:e0160251. doi: 10.1371/journal.pone.0160251 
57. St. Gelais C, de Silva S, Amie SM, Coleman CM, Hoy H, Hollenbaugh JA, et al. SAMHD1 restricts HIV-1 infection in dendritic cells (DCs) by dNTP depletion, but its expression in DCs and primary CD4+ Tlymphocytes cannot be upregulated by interferons. Retrovirology. (2012) 9:105. doi: 10.1186/1742-4690-9-105

58. Lahaye X, Satoh T, Gentili M, Cerboni S, Silvin A, Conrad C, et al. Nuclear envelope protein SUN2 promotes cyclophilin-a-dependent steps of HIV replication. Cell Rep. (2016) 15:879-92. doi: 10.1016/j.celrep.2016.03.074

59. Pertel T, Hausmann S, Morger D, Zuger S, Guerra J, Lascano J, et al. TRIM5 is an innate immune sensor for the retrovirus capsid lattice. Nature. (2011) 472:361-5. doi: 10.1038/nature09976

60. Portilho DM, Fernandez J, Ringeard M, Machado AK, Boulay A, Mayer M, et al. Endogenous TRIM5alpha function is regulated by SUMOylation and nuclear sequestration for efficient innate sensing in dendritic cells. Cell Rep. (2016) 14:355-69. doi: 10.1016/j.celrep.2015.12.039

61. Ben Haij N, Planes R, Leghmari K, Serrero M, Delobel P, Izopet J, et al. HIV1 tat protein induces production of proinflammatory cytokines by human dendritic cells and monocytes/macrophages through engagement of TLR4MD2-CD14 complex and activation of NF-kappaB pathway. PLoS ONE. (2015) 10:e0129425. doi: 10.1371/journal.pone.0129425

62. Cardinaud S, Urrutia A, Rouers A, Coulon PG, Kervevan J, Richetta C, et al. Triggering of TLR-3,-4, NOD2, and DC-SIGN reduces viral replication and increases T-cell activation capacity of HIV-infected human dendritic cells. Eur J Immunol. (2017) 47:818-29. doi: 10.1002/eji.201646603

63. Sironi M, Biasin M, Cagliani R, Forni D, De Luca M, Saulle I, et al. A common polymorphism in TLR3 confers natural resistance to HIV-1 infection. $J$ Immunol. (2012) 188:818-23. doi: 10.4049/jimmunol.1102179

64. Harman AN, Lai J, Turville S, Samarajiwa S, Gray L, Marsden V, et al. HIV infection of dendritic cells subverts the IFN induction pathway via IRF-1 and inhibits type 1 IFN production. Blood. (2011) 118:298308. doi: 10.1182/blood-2010-07-297721

65. Sun $\mathrm{L}, \mathrm{Wu} J$, Du F, Chen X, Chen ZJ. Cyclic GMP-AMP synthase is a cytosolic DNA sensor that activates the type I interferon pathway. Science. (2013) 339:786-91. doi: 10.1126/science.1232458

66. Gao D, Wu J, Wu YT, Du F, Aroh C, Yan N, et al. Cyclic GMP-AMP synthase is an innate immune sensor of HIV and other retroviruses. Science. (2013) 341:903-6. doi: 10.1126/science.1240933

67. Zhang H, Tang K, Zhang Y, Ma R, Ma J, Li Y, et al. Cell-free tumor microparticle vaccines stimulate dendritic cells via cGAS/STING signaling. Cancer Immunol Res. (2015) 3:196-205. doi: 10.1158/2326-6066.CIR-14-0177

68. Shu C, Li X, Li P. The mechanism of double-stranded DNA sensing through the cGAS-STING pathway. Cytokine Growth Factor Rev. (2014) 25:6418. doi: 10.1016/j.cytogfr.2014.06.006

69. Lahaye X, Satoh T, Gentili M, Cerboni S, Conrad C, Hurbain I, et al. The capsids of HIV-1 and HIV-2 determine immune detection of the viral cDNA by the innate sensor cGAS in dendritic cells. Immunity. (2013) 39:113242. doi: 10.1016/j.immuni.2013.11.002

70. Yoh SM, Schneider M, Seifried J, Soonthornvacharin S, Akleh RE, Olivieri KC, et al. PQBP1 is a proximal sensor of the cGAS-dependent innate response to HIV-1. Cell. (2015) 161:1293-305. doi: 10.1016/j.cell.2015.04.050

71. Bode C, Fox M, Tewary P, Steinhagen A, Ellerkmann RK, Klinman D, et al. Human plasmacytoid dentritic cells elicit a Type I Interferon response by sensing DNA via the cGAS-STING signaling pathway. Eur J Immunol. (2016) 46:1615-21. doi: 10.1002/eji.201546113

72. Paijo J, Doring M, Spanier J, Grabski E, Nooruzzaman M, Schmidt $\mathrm{T}$, et al. cGAS senses human cytomegalovirus and induces type I interferon responses in human monocyte-derived cells. PLoS Pathog. (2016) 12:e1005546. doi: 10.1371/journal.ppat.1005546

73. See P, Dutertre CA, Chen J, Gunther P, McGovern N, Irac SE, et al. Mapping the human DC lineage through the integration of high-dimensional techniques. Science. (2017) 356:eaag3009. doi: 10.1126/science.aag3009

74. Rodrigues PF, Alberti-Servera L, Eremin A, Grajales-Reyes GE, Ivanek R, Tussiwand R. Distinct progenitor lineages contribute to the heterogeneity of plasmacytoid dendritic cells. Nat Immunol. (2018) 19:711-22. doi: 10.1038/s41590-018-0136-9

75. Herman JS, Sagar, Grun D. FateID infers cell fate bias in multipotent progenitors from single-cell RNA-seq data. Nat Methods. (2018) 15:37986. doi: $10.1038 /$ nmeth. 4662
76. Martin-Gayo E, Gonzalez-Garcia S, Garcia-Leon MJ, Murcia-Ceballos A, Alcain J, Garcia-Peydro M, et al. Spatially restricted JAG1-Notch signaling in human thymus provides suitable DC developmental niches. J Exp Med. (2017) 214:3361-79. doi: 10.1084/jem.20161564

77. Lahaye X, Gentili M, Silvin A, Conrad C, Picard L, Jouve M, et al. NONO Detects the nuclear HIV capsid to promote cgas-mediated innate immune activation. Cell. (2018) 175:488-501.e22. doi: 10.1016/j.cell.2018.08.062

78. Martin-Gayo E, Cole MB, Kolb KE, Ouyang Z, Cronin J, Kazer SW, et al. A reproducibility-based computational framework identifies an inducible, enhanced antiviral state in dendritic cells from HIV-1 elite controllers. Genome Biol. (2018) 19:10. doi: 10.1186/s13059-017-1385-x

79. Harman AN, Nasr N, Feetham A, Galoyan A, Alshehri AA, Rambukwelle $\mathrm{D}$, et al. HIV blocks interferon induction in human dendritic cells and macrophages by dysregulation of TBK1. J Virol. (2015) 89:657584. doi: 10.1128/JVI.00889-15

80. Berg RK, Melchjorsen J, Rintahaka J, Diget E, Soby S, Horan KA, et al Genomic HIV RNA induces innate immune responses through RIGI-dependent sensing of secondary-structured RNA. PLoS ONE. (2012) 7:e29291. doi: 10.1371/journal.pone.0029291

81. Ablasser A, Bauernfeind F, Hartmann G, Latz E, Fitzgerald KA, Hornung V. RIG-I-dependent sensing of poly(dA:dT) through the induction of an RNA polymerase III-transcribed RNA intermediate. Nat Immunol. (2009) 10:1065-72. doi: 10.1038/ni.1779

82. Ahlers LR, Bastos RG, Hiroyasu A, Goodman AG. Invertebrate iridescent virus 6, a DNA virus, stimulates a mammalian innate immune response through RIG-I-like receptors. PLoS ONE. (2016) 11:e0166088. doi: 10.1371/journal.pone.0166088

83. Kaushik S, Teque F, Patel M, Fujimura SH, Schmidt B, Levy JA. Plasmacytoid dendritic cell number and responses to Toll-like receptor 7 and 9 agonists vary in HIV Type 1-infected individuals in relation to clinical state. AIDS Res Human Retroviruses. (2013) 29:501-10. doi: 10.1089/aid.2012.0200

84. Manches O, Fernandez MV, Plumas J, Chaperot L, Bhardwaj N. Activation of the noncanonical NF-kappaB pathway by HIV controls a dendritic cell immunoregulatory phenotype. Proc Natl Acad Sci USA. (2012) 109:141227. doi: 10.1073/pnas.1204032109

85. Tel J, Schreibelt G, Sittig SP, Mathan TS, Buschow SI, Cruz LJ, et al. Human plasmacytoid dendritic cells efficiently cross-present exogenous Ags to CD8+ T cells despite lower Ag uptake than myeloid dendritic cell subsets. Blood. (2013) 121:459-67. doi: 10.1182/blood-2012-06-435644

86. Granelli-Piperno A, Shimeliovich I, Pack M, Trumpfheller C, Steinman RM. HIV-1 selectively infects a subset of nonmaturing BDCA1-positive dendritic cells in human blood. J Immunol. (2006) 176:991-8. doi: 10.4049/jimmunol.176.2.991

87. van den Berg LM, Cardinaud S, van der Aar AM, Sprokholt JK, de Jong MA, Zijlstra-Willems EM, et al. Langerhans cell-dendritic cell cross-talk via langerin and hyaluronic acid mediates antigen transfer and cross-presentation of HIV-1. J Immunol. (2015) 195:1763-73. doi: 10.4049/jimmunol. 1402356

88. Dinter J, Duong E, Lai NY, Berberich MJ, Kourjian G, Bracho-Sanchez E, et al. Variable processing and cross-presentation of HIV by dendritic cells and macrophages shapes CTL immunodominance and immune escape. PLoS Pathog. (2015) 11:e1004725. doi: 10.1371/journal.ppat.1004725

89. Segura E, Touzot M, Bohineust A, Cappuccio A, Chiocchia G, Hosmalin A, et al. Human inflammatory dendritic cells induce Th17 cell differentiation. Immunity. (2013) 38:336-48. doi: 10.1016/j.immuni.2012.10.018

90. Coulon PG, Richetta C, Rouers A, Blanchet FP, Urrutia A, Guerbois $\mathrm{M}$, et al. HIV-infected dendritic cells present endogenous MHC class IIrestricted antigens to HIV-specific CD4+ T cells. J Immunol. (2016) 197:51732. doi: $10.4049 /$ jimmunol.1600286

91. Walker BD, Yu XG. Unravelling the mechanisms of durable control of HIV-1. Nat Rev Immunol. (2013) 13:487-98. doi: 10.1038/nri3478

92. Kwong PD, Mascola JR. Human antibodies that neutralize HIV-1: identification, structures, and B cell ontogenies. Immunity. (2012) 37:41225. doi: 10.1016/j.immuni.2012.08.012

93. Burton DR, Mascola JR. Antibody responses to envelope glycoproteins in HIV-1 infection. Nat Immunol. (2015) 16:571-6. doi: 10.1038/ni.3158

94. Doria-Rose NA, Klein RM, Daniels MG, O’Dell S, Nason M, Lapedes A, et al. Breadth of human immunodeficiency virus-specific neutralizing activity in 
sera: clustering analysis and association with clinical variables. J Virol. (2010) 84:1631-6. doi: 10.1128/JVI.01482-09

95. Locci M, Havenar-Daughton C, Landais E, Wu J, Kroenke MA, Arlehamn CL, et al. Human circulating PD-1+CXCR3-CXCR5+ memory Tfh cells are highly functional and correlate with broadly neutralizing HIV antibody responses. Immunity. (2013) 39:758-69. doi: 10.1016/j.immuni. 2013.08.031

96. Breitfeld D, Ohl L, Kremmer E, Ellwart J, Sallusto F, Lipp M, et al. Follicular B helper T cells express CXC chemokine receptor 5, localize to B cell follicles, and support immunoglobulin production. J Exp Med. (2000) 192:154552. doi: 10.1084/jem.192.11.1545

97. Morita R, Schmitt N, Bentebibel SE, Ranganathan R, Bourdery L, Zurawski G, et al. Human blood CXCR5(+)CD4(+) T cells are counterparts of T follicular cells and contain specific subsets that differentially support antibody secretion. Immunity. (2011) 34:108-21. doi: 10.1016/j.immuni.2011.01.009

98. Martin-Gayo E, Cronin J, Hickman T, Ouyang Z, Lindqvist M, Kolb $\mathrm{KE}$, et al. Circulating CXCR5+CXCR3+PD-1lo Tfh-like cells in HIV-1 controllers with neutralizing antibody breadth. JCI Insight. (2017) 2:e89574. doi: 10.1172/jci.insight.89574

99. Ma CS, Suryani S, Avery DT, Chan A, Nanan R, Santner-Nanan B, et al. Early commitment of naive human CD4(+) $\mathrm{T}$ cells to the $\mathrm{T}$ follicular helper (T(FH)) cell lineage is induced by IL-12. Immunol Cell Biol. (2009) 87:590600. doi: $10.1038 /$ icb. 2009.64

Conflict of Interest Statement: The authors declare that the research was conducted in the absence of any commercial or financial relationships that could be construed as a potential conflict of interest.

Copyright (c) 2019 Martin-Gayo and Yu. This is an open-access article distributed under the terms of the Creative Commons Attribution License (CC BY). The use, distribution or reproduction in other forums is permitted, provided the original author(s) and the copyright owner(s) are credited and that the original publication in this journal is cited, in accordance with accepted academic practice. No use, distribution or reproduction is permitted which does not comply with these terms. 